\title{
Aortic Intima-Media Thickness, Serum IGF-I, IGFBP-3, and Leptin Levels in Intrauterine Growth-Restricted Newborns of Healthy Mothers
}

\author{
ESAD KOKLU, MEHMET A. OZTURK, SELIM KURTOGLU, MUSTAFA AKCAKUS, ALI YIKILMAZ, AND TAMER GUNES
}

Department of Pediatrics [E.K., M.A.O., S.K., M.A., T.G.], Department of Radiology [A.Y.], Erciyes University, Kayseri, 38039, Turkey

\begin{abstract}
Neonates with intrauterine growth restriction (IUGR) are associated with reduced concentrations of IGF-I that might contribute to arterial wall thickening. Direct atherogenic effects of leptin have been described. We aimed to investigate the relationship among abdominal aortic intima-media thickness (aIMT), serum IGF-I, IGF binding protein-3, and leptin levels in neonates with IUGR. Abdominal aIMT was measured in 40 term neonates with IUGR and in 40 controls. Mean aIMT was significantly greater in neonates with IUGR $(0.45 \pm 0.03 \mathrm{~mm})$ than in controls $(0.39 \pm 0.04$ $\mathrm{mm}, p<0.0001)$. Serum IGF-I and leptin levels were lower in neonates with IUGR than in controls. There was a significant positive correlation between aIMT and gestational age, whereas a significant negative correlation was determined between aIMT and IGF-I in the IUGR neonates. For aIMT, significant associations included serum IGF-I level ( $\beta=-0.406, p=0.006)$ and gestational age $(\beta=0.331$, $p=0.022)$ in a multiple stepwise linear regression analysis. In control neonates, serum IGF-I levels were negatively related to aIMT $(\beta=-0.750, p<0.001)$. Neonates with IUGR have significant aIMT with decreased IGF-I. IGF-I levels determine aIMT not only in neonates with IUGR but also in healthy controls. (Pediatr Res 62: 704-709, 2007)
\end{abstract}

$\mathrm{I}^{\mathrm{n}}$ many studies, reduced birth weight seems to be associated with an increase in cardiovascular risk similar to that seen with major environmental risk factors, such as cigarette smoking or hypertension (1). Infants with low birth weights had elevated levels of the components of the insulin resistance syndrome in adult life (2), and they were found to be associated with lipid alteration that might increase the risk for cardiovascular disease (CVD) in adult life $(2,3)$. Although the clinical complications of atherosclerosis occur in adult life, the process of atherogenesis begins in childhood (4). In our previous study (5), we found that newborn babies with growth restriction had significant aortic thickening with hypertriglyceridemia.

The main established endocrine regulators of fetal growth include insulin and the IGF system $(6,7)$. As recently reviewed by Randhawa and Cohen (7), over the last decade it has been recognized that the IGF axis has a critical role in mediating fetal and postnatal growth. Alterations in growth hormone $(\mathrm{GH}) / \mathrm{IGF}-\mathrm{I}$ axis are associated with CVD. Growth hormone

Received January 18, 2007; accepted July 27, 2007.

Correspondence: Esad Koklu, M.D., Erciyes University, School of Medicine, Department of Pediatrics, Division of Neonatology, Kayseri/Turkey, 38039; e-mail: esad@erciyes.edu.tr

Erciyes University Research Fund supported this study. hypersecretion as well as GH deficiency are characterized by an increased prevalence of CVD (8). Insulin-like growth factor (IGF) I and IGF binding protein-3 (IGFBP-3) are circulating polypeptides traditionally thought to mediate growth hormone-induced longitudinal growth. Serum IGF-I levels correlate with the integrated 24-h secretion of GH and are considered better measures of the endogenous average secretion of GH because they lack circadian fluctuation (9). Low birth weight neonates are associated with increased sympathetic tone and lipid concentrations, and reduced concentrations of IGF-I, all of which might contribute to arterial wall thickening $(1,10)$.

The recently discovered hormone leptin, a $16-\mathrm{kD}$ adipocyte-derived protein encoded by the ob gene, is important for neuroendocrine regulation of body fat, feeding behavior, energy homeostasis, reproduction, puberty, and pregnancy. Dysregulation of autocrine/paracrine function of leptin at fetoplacento-maternal interface may be implicated in the pathogenesis of recurrent miscarriage, gestational diabetes, preeclampsia, and intrauterine growth restricted (IUGR) (11). Previous studies have demonstrated a positive association between infant size and cord leptin concentration (12). Beltowski (13) has extensively described the direct atherogenic effects of leptin in a review. Leptin exerts many potentially atherogenic effects such as induction of endothelial dysfunction stimulation of inflammatory reaction, oxidative stress, decrease in paraoxonase activity, platelet aggregation, migration, hypertrophy, and proliferation of vascular smooth muscle cells (14-20).

We presented the ultrasound-based measurement of distal segment of the dorsolateral aortic intima-media thickness (aIMT) in the newborns as a feasible, accurate, and sensitive marker of atherosclerosis risk (21). Additionally, we aimed to investigate the relationship among aIMT, serum IGF-I, IGFBP-3, and leptin levels in newborns with IUGR.

\section{METHODS}

Patients. From September 2005 to 2006, a total of 1592 neonates were admitted to the neonatal intensive care unit of Gevher Nesibe Hospital. The 
inclusion criterion at admission was neonate with IUGR and gestational age $\geq 37 \mathrm{wk}$. As premature babies have adult cardiovascular risk factors irrespective of intrauterine growth restricted (IUGR) (22), we excluded the preterm births before $37 \mathrm{wk}$. The exclusion criterions were being premature, a $<37 \mathrm{wk}$ gestational age, large for gestational age, asphyxiated at birth, and major congenital anomalies. Mothers whose pregnancies were complicated by hypertension and preeclampsia, or with maternal history of CVD or endocrine disorders such as diabetes, hypercholesterolemia, thyroid, or adrenal problems, or who had received alcohol were excluded. Infants whose mothers smoked or were taking drugs affecting the lipid metabolites, such as steroid and ritodrine, were excluded from the study. We aimed to minimize the effect of the intrauterine environment on aIMT. Neonates were classified as IUGR or appropriate for gestational age (AGA) neonates if birth weight was below 10th or between 10th and 90th percentile of mean gestational age-related intrauterine weight (23). Sixty-nine neonates with IUGR in the gestational age of interest were admitted. Of these, 16 infants were ineligible for the following reasons: asphyxiated at birth (6 infants), associated with major congenital anomalies (5 infants), with maternal history of endocrine disorders (4 infants), mothers who smoked (4 infants), mothers whose pregnancies were complicated by hypertension (4), and mothers who had received the listed drugs (2 infants). Nine infants had more than one reason. Of 53 eligible infants, in 13 infants the parents declined consent. Therefore, 40 neonates with IUGR (group 1) were included in the study. All fetuses of group 1 had at least two Doppler examinations during pregnancy. The last measurements were performed within $1 \mathrm{wk}$ before delivery. The Doppler examinations were considered normal in 35 fetuses. In three fetuses, there was reversal of end-diastolic velocities in the umbilical artery. Two fetuses were associated with cerebral redistribution, defined as the ratio of umbilical artery pulsatility index to middle cerebral artery pulsatility index greater than the 95th centile. A control group was formed by selecting the first healthy and AGA newborn, born immediately at Gevher Nesibe Hospital, after the admittance of each study infant who matched for gestational age $( \pm 10 \mathrm{~d})$. Someone not directly involved with the study formed the control group. Forty AGA infants with their healthy mothers (group 2) served as control. Informed consent was obtained from the parents before enrolment, and the project was approved by Erciyes University Hospital Committee for Research on Human Subjects. Gestational ages were determined from one or a combination of maternal menstrual dating, obstetrical ultrasound before $20 \mathrm{wk}$ of gestation, and Ballard score obtained at birth. Data concerning the mothers, their pregnancies, and deliveries were obtained from the records made by obstetricians and pediatricians according to the routine practice of the department of obstetrics and gynecology of Erciyes University hospital. Mean blood pressure measurements were obtained and an average of three measurements were calculated. The mean blood pressures of all infants were normal on the first day of birth. All the mothers and their neonates of groups 1 and 2 were healthy and they had no history of disease. Ponderal index (weight in grams $\times 100$ divided by the length in cubic centimeters) of the babies and pregravid body mass index $\left(B M I=\mathrm{kg} / \mathrm{m}^{2}\right)$ of the mothers were calculated.

Measurements of serum IGF-I, IGFBP-3, and leptin levels. All blood samples of the infants were collected within the first $2 \mathrm{~h}$ of life and before milk feeding or intravenous dextrose infusion. Serum was obtained by centrifugation at $4^{\circ} \mathrm{C}$ for $10 \mathrm{~min}$ and was then frozen at $-70^{\circ} \mathrm{C}$ until the time of assay. Serum leptin levels of the infants were measured by immunoradiometric assay (Diagnostic Systems Laboratories, Inc., Webster, TX) and results were expressed as nanograms per milliliter. Sensitivity was $0.1 \mathrm{ng} / \mathrm{mL}$, and the intra- and interassay coefficients of variation were $4.9 \%$ and $6.6 \%$, respectively. Serum IGFBP-3 and IGF-I levels were measured by RIA method (Biocode 1014, Biocode 1010, respectively, Liege, Belgium) and results were expressed as nanograms per milliliter. For IGF-I measurements, the minimum detectable concentration was $5 \mathrm{ng} / \mathrm{mL}$, intra- and interassay coefficients of variation were $3.4 \%$ and $8.4 \%$, respectively. For IGFBP-3 measurements, the minimum detectable concentration was $50 \mathrm{ng} / \mathrm{mL}$; intra- and interassay coefficients of variation were $5.6 \%$ and $8.2 \%$, respectively.

Ultrasound studies. Before beginning the ultrasound imaging, subjects were laid quietly in a dark, temperature-controlled room. The abdominal aortic artery was scanned according to a predetermined, standardized scanning protocol using a Shimadzu-1200xPLUS (Kyoto, Japan) high-resolution ultrasound mainframe with the use of linear array probes at 7.5 and $13 \mathrm{MHz}$. Two experienced vascular sonographers who were unaware of the clinical and laboratory characteristics of the neonates performed all the ultrasound studies. The aortic lumen diameter was defined as the line identifying the mediaadventitia interface in the near to the far wall. Abdominal aIMT was defined from the leading edge of the media-adventitia interface to the leading edge of the blood-intima interface. Aortic intima-media thickness was measured in a straight, nonbranched 1-cm longitudinal segment of the distal abdominal aorta. The measurements were performed in the manual analyzing system. The dorsal arterial wall of the most distal abdominal aorta was chosen for the area of interest because post mortem series have shown as the most lesionprone site (24). The abdominal aorta was first identified in upper abdomen using a $7.5-\mathrm{MHz}$ pediatric phased array transducer, and it was then followed distally until the aortic bifurcation was reached. The depth (anteroposterior direction) and location (cranio-caudal direction) of the distal $10 \mathrm{~mm}$ of the abdominal aorta was measured from these images and used as an aid to locate the aortic intima-media complex using a 13-MHz linear array transducer. For the assessment of aIMT, the image was focused on the far wall (dorsal arterial wall of the most distal $10 \mathrm{~mm}$ of the abdominal aorta), and gain settings were used to optimize image quality. Images $10 \mathrm{~mm}$ in width were magnified using a resolution box function. More than four images of the most distal 10-mm aortic far wall were captured in every case, and the images were digitally stored for subsequent off-line analysis. All images were taken at the enddiastole, incident with the R-wave on a continuously recorded ECG to minimize variability during the cardiac cycle (21). Four images of the best quality were chosen for each sonographer's analysis in each study subject. Four measurements covering the entire far wall segment of interest were taken for each image by two independent and blinded sonographers. Eighty separate newborns were examined two times by two sonographers. One observer was unaware of others results. Two pediatric radiologists selected the images for reading. The measurements of each sonographer were first averaged for each and then the average of both sonographers was used to calculate true means aIMT and aortic lumen diameter. Each observer measured aIMT of 80 infants four times. All measurements of aIMT were performed on the first day of birth.

Statistics. The between-observer and between-subject repeatability of aIMT measurements were analyzed by calculating the intraclass correlation coefficients. The intraclass correlation coefficient is an estimate of the reliability of the measurement and varies from 0 (no reliability) to 1 (total reliability, when test $=$ retest measure) $(25)$. The difference between the groups was evaluated by Student's independent samples $t$ tests. $\chi^{2}$ test was used to indicate within-group changes in proportions. Univariate analyses of each parameter on aIMT were performed with the simple linear regression model. To find independent factors for aIMT, multiple linear regression analyses by using stepwise method in overall groups, in group 1, and in group 2 were applied separately with aIMT as a dependent variable. In all tests, the $p$ value $<0.05$ was accepted as significant. All statistical analyses were done by using SPSS 10.0 for Windows (SPSS Inc., Chicago, IL).

\section{RESULTS}

Maternal and neonatal characteristics are shown in Table 1. Mean aIMT was significantly greater in neonates with IUGR $(0.45 \pm 0.03 \mathrm{~mm})$ than in controls $(0.39 \pm 0.04 \mathrm{~mm}, p<$ 0.0001; Table 1). Weight-adjusted mean aIMT was also compared, with difference between neonates with IUGR and control being even more pronounced $(0.19 \pm 0.02 \mathrm{~mm} / \mathrm{kg}$ versus $0.11 \pm 0.01 \mathrm{~mm} / \mathrm{kg}, p<0.0001$; Table 1). Aortic lumen diameter was higher in the neonates with IUGR than in controls ( $p=0.018$, Table 1). Serum IGF-I, IGFBP-3, and leptin levels of the neonates are shown in Table 1. Serum IGF-I and leptin levels were lower in neonates with IUGR than in controls ( $p=0.015$ and $p<0.001$, respectively; Table 1). The differences between the groups for aIMT, serum IGF-I, and leptin levels remained significant, even after we adjusted for birth weight and length (Table 1). The difference between the groups for weight-adjusted aIMT also remained significant, after we adjusted for length only (Table 1).

For all measurements, the between-observer variations of aIMT and aortic lumen diameter were similar. The between-observer intraclass correlation coefficients were measured as 0.93 (coefficients of variation, 5\%) and 0.94 (coefficients of variation, 5\%), respectively. The betweensubject intraclass correlation coefficients were measured as 0.94 (coefficients of variation, $4 \%$ ) and 0.95 (coefficients of variation, 4\%), respectively.

When a univariate analysis between aIMT and all study parameters in overall groups was performed, there were sig- 
Table 1. Characteristics of newborns and their mothers

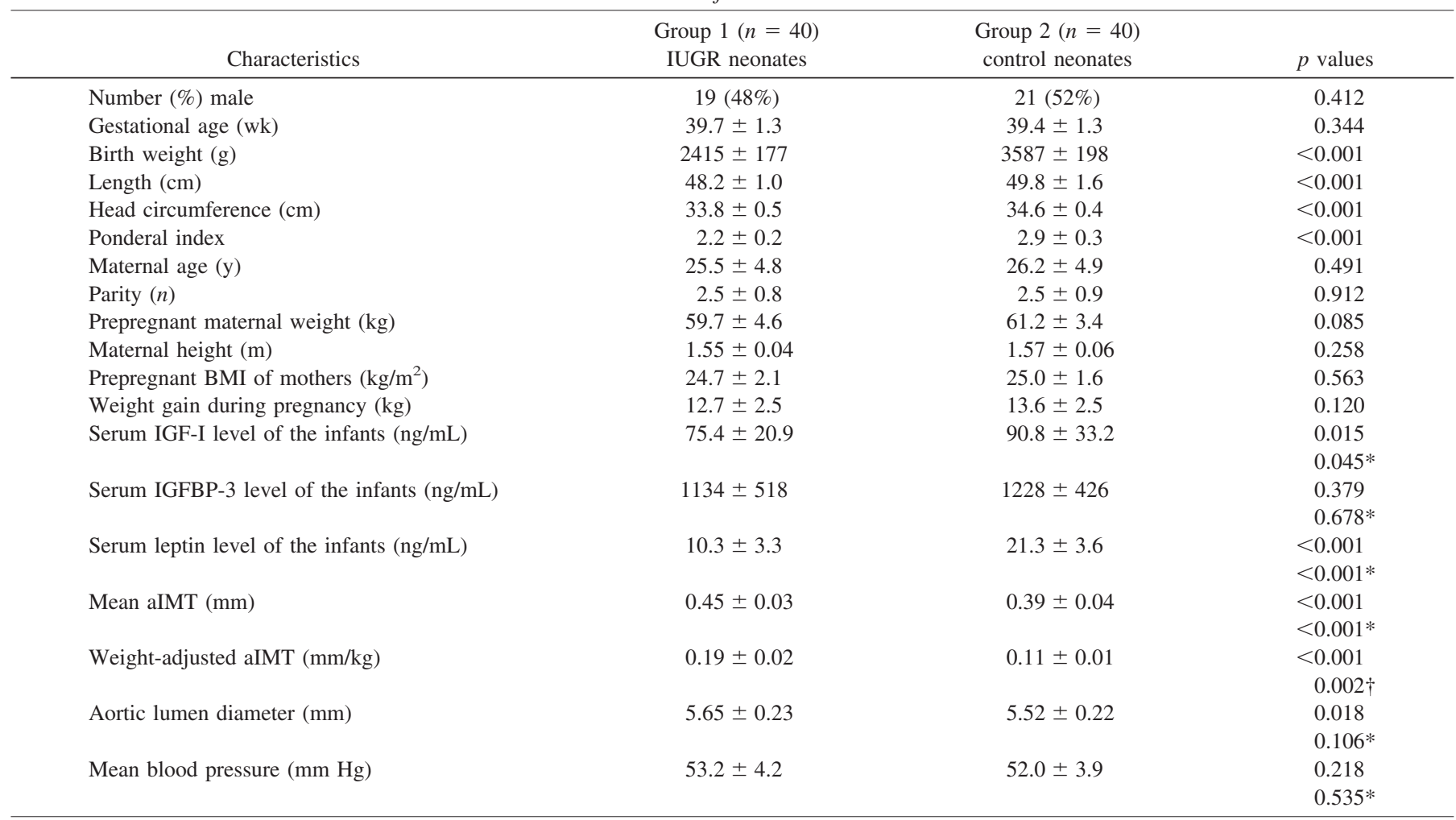

* After adjusted for birth weight and length.

$\dagger$ After adjusted for length only.

nificant negative correlations between aIMT and birth weight, length, head circumference, ponderal index, serum IGF, and leptin levels. There were significant positive correlations between aIMT and gestational age and aortic lumen diameter (Table 2). Birth weight was positively correlated with serum IGF-I $(r=0.333, p=0.003)$ and leptin levels $(r=0.822$, $p<0.001)$. When a univariate analysis between aIMT and all study parameters in group 1 (IUGR neonates) was performed, there was a significant negative correlation between aIMT and serum IGF level, there was a significant positive correlation between aIMT and gestational age (Table 2). In healthy neonates (group 2), serum IGF-I level was negatively related to aIMT on the univariate analysis (Table 2).

The multiple (stepwise) regression analysis for models predicting aIMT in overall groups, in group 1 (IUGR neonates), and in group 2 (control neonates) is shown in Table 3. When a multiple linear regression analysis by using stepwise method in overall groups $(n=80)$ was performed with aIMT as a dependent variable, and gestational age, gender, birth weight, length, head circumference, aortic lumen diameter,

Table 2. Simple linear regression analysis of mean aortic intima-media thickness in overall groups, in group 1, and in group 2

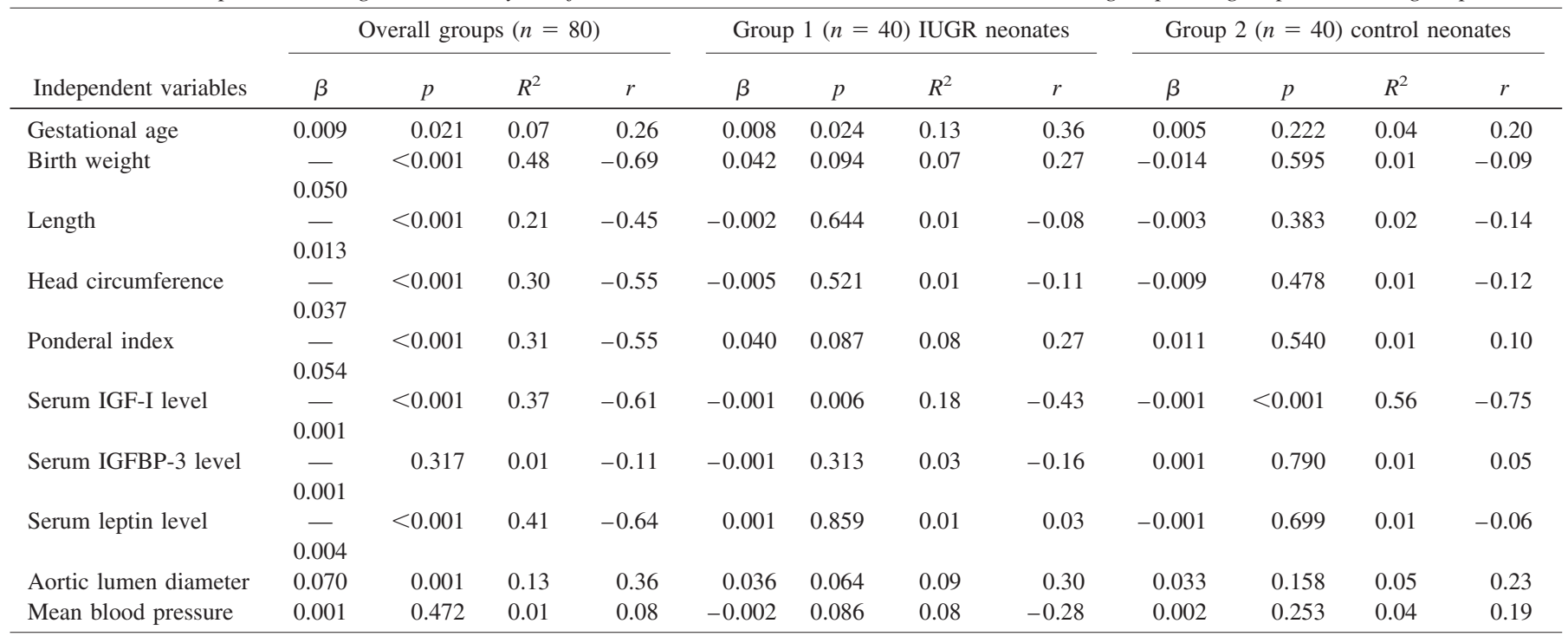


Table 3. The multiple (stepwise) regression analysis for models predicting aIMT in overall groups, in group 1, and in group 2

\begin{tabular}{|c|c|c|c|c|c|c|}
\hline Predicting variable & $\begin{array}{l}\text { Unstandardized } \\
\text { coefficient } \beta\end{array}$ & $\begin{array}{l}\text { Standardized } \\
\text { coefficient } \beta\end{array}$ & $p$ & $R^{2}$ & $\begin{array}{c}\text { Partial } \\
\text { correlation }\end{array}$ & $\begin{array}{l}\text { Pearson } \\
\text { correlation }\end{array}$ \\
\hline \multicolumn{7}{|l|}{ Overall groups $(n=80)$} \\
\hline Birth weight & -0.038 & -0.518 & $<0.001$ & 0.668 & -0.641 & -0.691 \\
\hline Aortic lumen diameter & 0.033 & 0.170 & 0.015 & & 0.274 & 0.363 \\
\hline \multicolumn{7}{|c|}{ Group $1(n=40)$ IUGR neonates } \\
\hline IGF-I & -0.001 & -0.406 & 0.006 & 0.292 & -0.434 & -0.428 \\
\hline IGF-I & -0.001 & -0.750 & $<0.001$ & 0.562 & -0.750 & -0.750 \\
\hline
\end{tabular}

serum IGF-I, and leptin levels as independent variables, significant correlations included birth weight, serum IGF-I level, and aortic lumen diameter (Table 3). When a multiple linear regression analysis by using stepwise method in the IUGR neonates $(n=40)$ was performed with aIMT as a dependent variable and gestational age, serum IGF-I level, gender as independent variables, significant correlations included serum IGF-I level and gestational age (Table 3).

\section{DISCUSSION}

We found that IUGR neonates have significant aIMT and aortic lumen diameter with decreased serum IGF-I and leptin levels. Mean aIMT was negatively correlated with serum IGF-I and was positively correlated with gestational age in the neonates with IUGR. Serum IGF-I levels were also negatively related to aIMT in control neonates. IGF-I levels determine aIMT not only in neonates with IUGR but also in healthy controls.

Birth weight was positively correlated with serum IGF-I and leptin levels in the present study. Yang et al. (26) found that, among term babies, levels of IGF-I and IGFBP-3 showed significant correlation with birth weight and length. Previous studies have demonstrated a positive relationship between cord serum IGF-I concentration and birth weight within the normal range and reduced IGF-I concentrations in infants with IUGR (27), and these results are in agreement with our findings. However, our findings are in contrast with Wang et al. (28), who found that the concentration of serum IGF-I showed an inverse correlation with birth weight; the mean serum IGF-I levels in the small for gestational age (SGA) group were significantly higher than those in AGA neonates. Additionally, Davidson et al. (29) found that there were no significant differences in serum IGF-I and IGFBP-3 levels between AGA and SGA infants. At birth, cord blood leptin is strongly correlated with birth weight (12). Fetal leptin levels are also correlated with fetal growth; leptin levels in growthretarded fetuses are lower than in controls $(12,30)$, and these results are in agreement with our findings. However, Shekhawat et al. (31) found that SGA infants had increased leptin level.

In agreement with the results of our previous study (5), we found that aIMT was significantly increased in neonates with IUGR compared with AGA neonates. Skilton et al. (10) found that maximum aIMT was significantly higher in the babies with IUGR than in those without. In 1989, Barker and col- leagues (1) postulated that low birth weight was an important and unrecognized risk factor for increased cardiovascular risk in adult life. In addition to postnatal events, impaired intrauterine growth might affect arterial development. Atheromatous changes have been documented histopathologically by early childhood, especially in the abdominal aorta, and it is now possible to measure aortic wall thickness accurately and reproducibly in vivo with external ultrasonography (24). The early vascular changes include thickening of vessel walls and impairment of arterial vasodilatory function as assessed by noninvasive ultrasound technique (32). Studies in children with hypercholesterolemia have demonstrated increased carotid intima-media thickness (cIMT) compared with control (33). The carotid artery has been the target in these studies because it is located rather superficially on the neck and can be easily visualized by ultrasound. The first atherosclerotic lesions usually actually begin to develop in the abdominal aorta (24). Because it is now possible to visualize the abdominal aorta and accurately assess its aIMT, measuring aIMT might provide a better index of preclinical atherosclerosis in highrisk children than cIMT. Low birth weight neonates are associated with increased sympathetic tone and lipid concentrations, and reduced concentrations of IGF-I, all of which might contribute to arterial wall thickening (1). An important confounding factor could also be the lipid profile in the newborns, which might have been altered because of IUGR. However, the lipid profile was not determined in the present study. In our previous study (5), we found that IUGR neonates had significant maximum aortic thickening with hypertriglyceridemia. We found that mean aortic wall thickness and aortic lumen diameter were significantly increased in neonates with IUGR, and there was nearly positive correlation between aIMT and aortic lumen diameter in these neonates. In these neonates, the blood flow is probably increased, therefore modifying the arterial level of stress that can lead to geometric and phenotypic arterial changes. Increase of artery diameter seems to maintain a constant wall stress.

Serum IGF-I levels of the infants was negatively correlated with aIMT in the present study. There are several potential mechanisms by which IGF-I could modify atherosclerotic processes, either locally or in a systemic manner (34). Ruotolo et al. (35) showed that serum IGF-I levels were positively associated with the progression of premature coronary artery disease and suggested that this might, at least partly, be caused by the effects of IGF-I on the proliferation and migration of 
vascular smooth muscle cells. A positive association between cIMT and high IGF-I levels has also been observed in acromegalic patients (36). It has not been clarified yet how the excess of GH/IGF-I induces intima-media thickening, but the process could partly be attributed to the direct effects of IGF-I on vascular smooth muscle cells (37). In our previous studies, we found that macrosomic neonates of diabetic mothers have significantly increased aIMT $(38,39)$ with higher lipid $(38)$, IGF-I (39), and leptin (39) concentrations. Macrosomic neonates born to diabetic mothers are associated with increased lipid (38), IGF-I, and leptin levels $(39,40)$, all of which might contribute to arterial wall thickening $(38,39)$. However, aIMT was negatively correlated with IGF-I in the present study. It may be because GH hypersecretion as well as GH deficiency are characterized by an increased prevalence of CVD (8). In agreement with our findings, Colao et al. (41) found that IGF-I levels determine IMT in both patients with IGF-I deficiency and healthy controls. IGF-I plays an important role with regard to the endothelium and increases nitric oxide production (42). Decreased nitric oxide activity is associated with intimal thickening (43).

As we have excluded those with secondary IUGR, the sample studied is no longer representative of most cases of IUGR. Although we obtained fairly reproducible results when using manual placement of electronic calipers for IMT measurement, the use of newer computer-assisted automated IMT image analysis and measurement would be preferable for better accuracy in future studies. The measurement of IMT in an artery suffers from the inability to assess whether an increase in IMT represents atherosclerosis (intimal thickening) or vascular hypertrophy (medial thickening) or both. The mean intima/media ratio was 0.1 just after birth and increased continuously to the second postnatal year. Replication of medial smooth muscle cells has been shown to be high before birth and to decrease between birth and 2 y of age (44). Separate measurement of intima thickness and media thickness and calculation of the intima/media ratio would be very useful but are currently unattainable in noninvasive techniques in neonates and adults.

In conclusion, neonates with IUGR have significant aIMT with decreased IGF-I levels. IGF-I levels determine aIMT not only in neonates with IUGR but also in healthy controls. These results should be confirmed in larger and longitudinal investigations.

Acknowledgments. The authors thank Professor Ahmet Ozturk (Department of Biostatistics, Erciyes University) and Associate Professor Abdulhakim Coskun (Department of Radiology, Division of Pediatric Radiology, Erciyes University) for help with statistical evaluation and selection of the images for reading, respectively.

\section{REFERENCES}

1. Barker DJ, Winter PD, Osmond C, Margetts B, Simmonds SJ 1989 Weight in infancy and death from ischaemic heart disease. Lancet 2:577-580

2. Mi J, Law C, Zhang KL, Osmond C, Stein C, Barker D 2000 Effects of infant birth weight and maternal body mass index in pregnancy on components of the insulin resistance syndrome in China. Ann Intern Med 132:253-260
3. Molina M, Casanueva V, Cid X, Ferrada MC, Perez R, Dios G, Reyes M, Venegas H, Cid L 2000 Lipid profile in newborns with intrauterine growth retardation. Rev Med Chil 128:741-748

4. Gordon T, Kannel WB 1971 Premature mortality from coronary heart disease. The Framingham Study. JAMA 215:1617-1625

5. Koklu E, Kurtoglu S, Akcakus M, Koklu S, Buyukkayhan D, Gumus H, Yikilmaz A 2006 Increased aortic intima-media thickness is related to lipid profile in newborns with intrauterine growth restriction. Horm Res 65:269-275

6. Christou H, Connors JM, Ziotopoulou M, Hatzidakis V, Papathanassoglou E, Ringer SA, Mantzoros CS 2001 Cord blood leptin and insulin-like growth factor levels are independent predictors of fetal growth. J Clin Endocrinol Metab 86:935-938

7. Randhawa R, Cohen P 2005 The role of the insulin-like growth factor system in prenatal growth. Mol Genet Metab 86:84-90

8. Lombardi G, Colao A, Marzullo P, Ferone D, Longobardi S, Esposito V, Merola B 1997 Is growth hormone bad for your heart? Cardiovascular impact of GH deficiency and of acromegaly. J Endocrinol 155:S33-S37

9. Johansson AG, Forslund A, Hambraeus L, Blum WF, Ljunghall S 1994 Growth hormone-dependent insulin-like growth factor binding protein is a major determinant of bone mineral density in healthy men. J Bone Miner Res 9:915-921

10. Skilton MR, Evans N, Griffiths KA, Harmer JA, Celermajer DS 2005 Aortic wall thickness in newborns with intrauterine growth restriction. Lancet 365:1484-1486

11. Bajoria R, Sooranna SR, Ward BS, Chatterjee R 2002 Prospective function of placental leptin at maternal-fetal interface. Placenta 23:103-115

12. Varvarigou A, Mantzoros CS, Beratis NG 1999 Cord blood leptin concentrations in relation to intrauterine growth. Clin Endocrinol (Oxf) 50:177-183

13. Beltowski J 2006 Leptin and atherosclerosis. Atherosclerosis 189:47-60

14. Lembo G, Vecchione C, Fratta L, Marino G, Trimarco V, d'Amati G, Trimarco B 2000 Leptin induces direct vasodilation through distinct endothelial mechanisms. Diabetes 49:293-297

15. Vecchione C, Maffei A, Colella S, Aretini A, Poulet R, Frati G, Gentile MT, Fratta L, Trimarco V, Trimarco B, Lembo G 2002 Leptin effect on endothelial nitric oxide is mediated through Akt-endothelial nitric oxide synthase phosphorylation pathway. Diabetes 51:168-173

16. Shamsuzzaman AS, Winnicki M, Wolk R, Svatikova A, Phillips BG, Davison DE, Berger PB, Somers VK 2004 Independent association between plasma leptin and C-reactive protein in healthy humans. Circulation 109:2181-2185

17. Watson AM, Poloyac SM, Howard G, Blouin RA 1999 Effect of leptin on cytochrome P-450, conjugation, and antioxidant enzymes in the ob/ob mouse. Drug Metab Dispos 27:695-700

18. Be€towski J, Wojcicka G, Jamroz A 2003 Leptin decreases plasma paraoxonase (PON1) activity and induces oxidative stress: the possible novel mechanism for proatherogenic effect of chronic hyperleptinemia. Atherosclerosis 170:21-29

19. Konstantinides S, Schafer K, Koschnick S, Loskutoff DJ 2001 Leptin dependent platelet aggregation and arterial thrombosis suggests a mechanism for atherothrombotic disease in obesity. J Clin Invest 108:1533-1540

20. Shin HJ, Oh J, Kang SM, Lee JH, Shin MJ, Hwang KC, Jang Y, Chung JH 2005 Leptin induces hypertrophy via p38 mitogen-activated protein kinase in rat vascular smooth muscle cells. Biochem Biophys Res Commun 329:18-24

21. Jarvisalo MJ, Jartti L, Nanto-Salonen K, Irjala K, Ronnemaa T, Hartiala JJ, Celermajer DS, Raitakari OT 2001 Increased aortic intima-media thickness: a marker of preclinical atherosclerosis in high-risk children. Circulation 104:29432947

22. Irving RJ, Belton NR, Elton RA, Walker BR 2000 Adult cardiovascular risk factors in premature babies. Lancet 355:2135-2136

23. Lubchenco LO, Hansman C, Boyd E 1966 Intrauterine growth in length and head circumference as estimated from live births at gestational ages from 26 to 42 weeks. Pediatrics 37:403-408

24. McGill HC Jr, McMahan CA, Herderick EE, Tracy RE, Malcom GT, Zieske AW, Strong JP 2000 Effects of coronary heart disease risk factors on atherosclerosis of selected regions of the aorta and right coronary artery. PDAY Research Group Pathobiological Determinants of Atherosclerosis in Youth. Arterioscler Thromb Vasc Biol 20:836-845

25. SAS/STAT User's Guide 1998 SAS Institute Inc., Cary, NC

26. Yang SW, Yu JS 2000 Relationship of insulin-like growth factor-I, insulin-like growth factor binding protein-3, insulin, growth hormone in cord blood and maternal factors with birth height and birth weight. Pediatr Int 42:31-36

27. Ogilvy-Stuart AL, Hands SJ, Adcock CJ, Holly JM, Matthews DR, Mohamed-Ali V, Yudkin JS, Wilkinson AR, Dunger DB 1998 Insulin, insulin-like growth factor I (IGF-I), IGF-binding protein-1, growth hormone, and feeding in the newborn. J Clin Endocrinol Metab 83:3550-3557

28. Wang HS, Lim J, English J, Irvine L, Chard T 1991 The concentration of insulin-like growth factor-I and insulin-like growth factor-binding protein-1 in human umbilical cord serum at delivery: relation to fetal weight. J Endocrinol 129:459-464

29. Davidson S, Shtaif B, Gil-Ad I 2001 Insulin, insulin-like growth factors-I and -II and insulin-like growth factor binding protein-3 in newborn serum: association with normal fetal head growth and head circumference. J Pediatr Endocrinol Metab $14: 151-158$

30. Cinaz P, Sen E, Bideci A, Ezgu FS, Atalay Y, Koca E 1999 Plasma leptin levels of large for gestational age and small for gestational age infants. Acta Paediatr 88:753-756

31. Shekhawat PS, Garland JS, Shivpuri C, Mick GJ, Sasidharan P, Pelz CJ, McCormick KL 1998 Neonatal cord blood leptin: its relationship to birth weight, body mass index, maternal diabetes, and steroids. Pediatr Res 43:338-343

32. Raitakari OT 1999 Imaging of subclinical atherosclerosis in children and young adults. Ann Med 31:33-40 
33. Tonstad S, Joakimsen O, Stensland-Bugge E, Leren TP, Ose L, Russell D, Bonaa KH 1996 Risk factors related to carotid intima-media thickness and plaque in children with familial hypercholesterolemia and control subjects. Arterioscler Thromb Vasc Biol 16:984-991

34. Bayes-Genis A, Conover CA, Schwartz RS 2000 The insulin-like growth factor axis: a review of atherosclerosis and restenosis. Circ Res 86:125-130

35. Ruotolo G, Bavenholm P, Brismar K, Efendic S, Ericsson CG, de Faire U, Nilsson J, Hamsten A 2000 Serum insulin-like growth factor-I level is independently associated with coronary artery disease progression in young male survivors of myocardial infarction: beneficial effects of bezafibrate treatment. J Am Coll Cardiol 35:647-654

36. Colao A, Spiezia S, Cerbone G, Pivonello R, Marzullo P, Ferone D, Di Somma C, Assanti AP, Lombardi G 2001 Increased arterial intima-media thickness by B-M mode echodoppler ultrasonography in acromegaly. Clin Endocrinol (Oxf) 54:515-524

37. Brevetti G, Marzullo P, Silvestro A, Pivonello R, Oliva G, di Somma C, Lombardi G, Colao A 2002 Early vascular alterations in acromegaly. J Clin Endocrinol Metab $87: 3174-3179$

38. Koklu E, Akcakus M, Kurtoglu S, Koklu S, Yikilmaz A, Coskun A, Gunes T 2007 Aortic intima-media thickness and lipid profile in macrosomic newborns. Eur J Pediatr 166:333-338
39. Koklu E, Kurtoglu S, Akcakus M, Yikilmaz A, Gunes T 2007 Serum insulin-like growth factor-I (IGF-I) IGF binding protein-3 (IGFBP-3) and leptin levels are related to abdominal aortic intima-media thickness in macrosomic newborns. Growth Horm IGF Res 17:26-32

40. Eidelman AI, Samueloff A 2002 The pathophysiology of the fetus of the diabetic mother. Semin Perinatol 26:232-236

41. Colao A, Di Somma C, Filippella M, Rota F, Pivonello R, Orio F, Vitale G, Lombardi G 2004 Insulin-like growth factor-1 deficiency determines increased intima-media thickness at common carotid arteries in adult patients with growth hormone deficiency. Clin Endocrinol (Oxf) 61:360-366

42. Walsh MF, Barazi M, Pete G, Muniyappa R, Dunbar JC, Sowers JR 1996 Insulinlike growth factor-I diminishes in vivo and in vitro vascular contractility: role of vascular nitric oxide. Endocrinology 137:1798-1803

43. Gryglewski RJ, Palmer RM, Moncada S 1986 Superoxide anion is involved in the breakdown of endothelium-derived vascular relaxing factor. Nature 320:454456

44. Ikari Y, McManus BM, Kenyon J, Schwartz SM 1999 Neonatal intima formation in the human coronary artery. Arterioscler Thromb Vasc Biol 19:20362040 